\title{
Journal of Applied Statistics
}

\section{EDITOR}

Gopal K. Kanji, Sheffield Hallam University, UK

Supported by an International Editorial Board

Journal of Applied Statistics provides a forum for communication between both applied statisticians and users of applied statistical techniques across a wide range of disciplines. These areas include business, computing, economics, ecology, education, management, medicine, operational research and sociology, but papers from other areas are also considered. The editorial policy is to publish rigorous but clear and accessible papers on applied techniques. Purely theoretical papers are avoided but those on theoretical developments which clearly demonstrate significant applied potential are welcomed. Each journal issue aims for a balance of methodological innovation, thorough evaluation of existing techniques, case studies, speculative articles, book reviews and letters.

This journal is also available online.

Please connect to http://www.tandf.co.uk/online.html for further information.

\section{SUBSCRIPTION RATES}

2001 - Volume 28 (8 issues)

Print ISSN 0266-4763

Online ISSN 1360-0532

Institutional rate: US\$1075; $£ 652$ (includes free online access)

Personal rate: US\$290; $£ 177$ (print only)

\section{ORDER FORM}

PLEASE COMPLETE IN BLOCK CAPITALS AND RETURN TO THE ADDRESS BELOW

Please invoice me at the $\square$ institutional rate $\square$ personal rate

$\square$ Please send me a sample copy

Name

Address

E-mail 


\title{
Total Quality Management
}

\author{
EDITOR \\ Professor Gopal K. Kanji \\ Sheffield Hallam University, UK
}

Supported by an International Editorial Board

Total Quality Management is an international journal which sets out to stimulate thought and research in all aspects of total quality management and to provide a natural forum for discussion and dissemination of research results. The journal is designed to encourage interest in all matters relating to total quality management and is intended to appeal to both the academic and professional community working in this area.

Total quality management is the culture of an organization committed to customer satisfaction through continuous improvement. This culture varies both from one country to another and between different industries, but has certain essential principles which can be implemented to secure greater market share, increased profits and reduced costs.

The journal provides up-to-date research, consultancy work and case studies right across the broad field of quality culture, quality strategy, quality systems, tools and techniques of total quality management and its implementation in both the manufacturing and service sectors.

This journal is also available online.

Please connect to http://www.tandf.co.uk/online.html for further information.

\section{SUBSCRIPTION RATES}

2001 - Volume 12 (8 issues)

Print ISSN 0954-4127

Online ISSN 1360-0613

Institutional rate: US\$859; $£ 499$ (includes free online access)

Personal rate: US\$292; $£ 177$ (print only)

\section{ORDER FORM}

PLEASE COMPLETE IN BLOCK CAPITALS AND RETURN TO THE ADDRESS BELOW

Please invoice me at the $\square$ institutional rate $\square$ personal rate

$\square$ Please send me a sample copy

Name

Address

E-mail 


\title{
Journal of Risk Research
}

\section{EDITOR}

Ragnar Löfstedt, University of Surrey, Guildford, UK

BOOK REVIEW EDITOR

Jonathan Sime, Jonathan Sime Associates (JSA), Surrey, UK (Visiting Professor, University of Ulster, Northern Ireland)

\author{
ASSOCIATE EDITORS \\ Louis Goossens, Delft University, The Netherlands \\ Philippe Hubert, CEA IPSN DHPD SEGR, BP 6 Fontenay Aus Roses, France \\ Saburo Ikeda, Tsukuba University, Ibaraki, Japan \\ Roger Kasperson, lark University, Worcester, USA \\ Joanne Linnerooth-Bayer, IIASA, Laxenburg, Austria \\ Lennart Sjöberg, Stockholm School of Economics, Stockholm, Sweden
}

\section{Supported by an International Editorial Board}

The Journal of Risk Research is the official journal of the Society for Risk Analysis Europe and the Society for Risk Analysis Japan. It is a quarterly international journal which publishes peer reviewed theoretical and empirical research articles within the risk field from the areas of engineering, physical, health and social sciences, as well as articles related to decision making, regulation and policy issues in all disciplines. Articles will be published in English. The main aims of the Journal of Risk Research are to stimulate intellectual debate on risk within Europe, Japan and elsewhere, to promote better risk management practices and to contribute to the development of risk management methodologies.

This journal is also available online.

Please connect to http://www.tandf.co.uk/online.html for further information.

\section{SUBSCRIPTION RATES}

2001 - Volume 4 (4 issues)

Print ISSN 1366-9877

Online ISSN 1466-4461

Institutional rate: US\$371; $£ 225$ (includes free online access)

Personal rate: US\$74; $£ 41$ (print only)

\section{ORDER FORM}

PLEASE COMPLETE IN BLOCK CAPITALS AND RETURN TOTHE ADDRESS BELOW

Please invoice me at the $\square$ institutional rate $\square$ personal rate

$\square$ Please send me a sample copy

Name

Address

E-mail 


\section{Venture Capital}

\section{An International Journal of Entrepreneurial Finance}

\section{EDITORS}

Professor Colin Mason

Department of Geography, University of Southampton,

Highfield, Southampton SO17 1BJ, UK

\section{Professor Richard Harrison}

University of Aberdeen, Scotland

Venture Capital: An International Journal of Entrepreneurial Finance publishes cutting edge, research-based papers from academics and practitioners on all aspects of private equity finance-institutional venture capital, informal venture capital, corporate venture capital, public sector venture capital and community venture capital, and on all aspects of the venture capital process from investment decision to exit, including studies on investment patterns, investment decision-making, investment performance, realization of investment value, exit routes (including the relationship with junior capital markets such as NASDAQ, EASDAQ, AIM and Nouvelle Marché), economic impact and public policy. It seeks to publish papers from a wide range of disciplinary perspectives which use a variety of research methods.

The emphasis will be on publishing papers of high academic quality. Submitted papers will normally be reviewed by the editors and two referees.

This journal is also available online. Please connect to http://www.tandf.co.uk/online.html for further information.

\section{SUBSCRIPTION RATES}

2001 - Volume 3 (4 issues)

Print ISSN 1369-1066

Online ISSN 1464-5343

Institutional: US\$382; $£ 231$ (includes free online access)

Personal: US\$84; $£ 52$ (print only)

\section{ORDER FORM}

PLEASE COMPLETE IN BLOCK CAPITALS AND RETURN TOTHEADDRESS BELOW

Please invoice me at the $\square$ institutional rate $\square$ personal rate

$\square$ Please send me a sample copy

Name

Address

E-mail 


\section{INFORMATION FOR CONTRIBUTORS}

Business and Politics welcomes original articles, cases, and commentaries that are not being considered by another journal for publication. Articles will be evaluated by the Editors to establish whether they fit with the journal's objectives and will then be reviewed by anonymous referees. Authors can expect to be informed of the Editors' decision within three months of submission. Manuscripts should be submitted to any of the three regional offices listed below.

\author{
Americas Submission Address \\ Professor Emerson Tiller \\ Editor, Business and Politics \\ Graduate School of Business \\ CBA 5.202 \\ University of Texas \\ Austin, Texas 78712, USA \\ Tel: +15124715258 \\ Fax: +1 5124710587 \\ E-mail: tiller@mail.utexas.edu
}

Asia and the Pacific Submission Address

Professor John Ravenhill

Associate Editor, Business and Politics

Department of Politics

University of Edinburgh

31 Buccleuch Place

Edinburgh EH8 9JT, UK

Tel. (Direct) +44 (0) 131 650-4266

Fax +44 (0) 131 650-6546

E-mail: j. ravenhill@ed.ac.uk

\author{
Europe and Africa Submission Address \\ Professor Cédric Dupont \\ Associate Editor, Business and Politics \\ Graduate Institute of International Studies \\ 11a, Avenue de la Paix \\ 1202 Geneva, Switzerland \\ Tel: +41 227348950 \\ Fax: +41 227333049 \\ E-mail: dupont@hei.unige.ch
}

\author{
Further enquiries or correspondence may \\ be directed to: \\ Professor Vinod K. Aggarwal \\ Editor-in-Chief, Business and Politics \\ 802 Barrows Hall \#1970 \\ University of California \\ Berkeley, California 94720-1970, USA \\ Tel: +1 5106431732 \\ Fax: +1 5106431746 \\ E-mail: bap@socrates.berkeley.edu
}

Submissions: All papers should be submitted in triplicate. An abstract should be included on a separate page. We encourage authors to also send a copy of their manuscript in electronic form, either by e-mail or on a 3.5 inch floppy disk. Where possible, the file should be saved in the 'Word for Windows' format.

Presentation: Manuscripts should be double spaced throughout and single-sided. Please allow for generous margins and number all pages consecutively. The author should retain a copy, as submitted manuscripts cannot be returned. All papers should include a word count. Full names of the author(s) should be given, an address for correspondence, and where possible a contact telephone number, facsimile number, and e-mail address. Current and recent academic and professional affiliations should be supplied, together with a list of major publications (with dates and name of publisher) and forthcoming books.

Style: Please refer to the Business and Politics style guide, which can be found under "Instructions for authors" on the Business and Politics website (http://www.tandf.co.uk/journals/carfax/13695258.html), for information regarding footnotes, references, and other matters of stule. For questions not answered in the stule guide, please refer to The Chicago Manual of Style, $14^{\text {th }} \mathrm{ed}$, or contact the BAP editorial office.

Tables and figures: should be prepared on separate sheets using originals where possible; they should not be included within the text. The author(s) should indicate clearly in the margin of the paper where tables and figures are to be inserted. Each table and figure should be numbered consecutively in Arabic numerals with an appropriate caption (e.g. Table 1, Table 2; Figure 1, Figure 2, and so on). Permission to reproduce copyright material must be obtained by the author(s) prior to submission and any acknowledgements should be included either in the text or the caption as appropriate. A camera ready copy of any tables and figures should be submitted in addition to those attached to the manuscripts.

Proofs: Authors are expected to correct and return proofs of accepted articles within 48 hours of receipt.

Offprints: Authors are entitled to 50 free offprints of their article and a copy of the issue in which their article appears. Offprints may take 3-4 weeks to deliver after publication.

Copyright: It is a condition of publication that authors vest copyright in their articles, including abstracts, in Taylor \& Francis Ltd. This enables us to ensure full copyright protection and to disseminate the article, and the journal, to the widest possible readership in print and electronic formats as appropriate. Authors may, of course use the article elsewhere after publication providing that prior permission is obtained from Taylor \& Francis Ltd. Authors are themselves responsible for obtaining permission to reproduce copyright material from other sources. 


\section{BUSINESS POLITICS}

\section{Volume 3 Number 1 April 2001}

\section{ARTICLES}

Globalization or National Capitalism: Large Firms, National Strategies, and Political Activities Wendy L. Hansen \& Neil J. Mitchell

The Fallacy of Regulatory Symmetry: An Economic Analysis of the 'Level Playing Field' in Cable TV Franchising Statutes Thomas W. Hazlett \& George S. Ford

The Political Preferences of Diversified Business Groups: Lessons from Colombia (1994-1998) Angelika Rettberg

Exploring the Political Economy of Consumer Legislation: The Development of Automobile Lemon Laws Brian Shaffer \& Daniel T. Ostas 